Henry ii of France, whose issue-male of the direct line is wholly extinct; but yet for that the French do pretend their Law Salique to exclude women (which we English have ever denied to be good until now) hereby cometh it to pass that the king of Navarr pretendeth to enter, and to be preferred before the said Infanta, or her sister's children, though male, by a collateral line. But yet her favourers say, (I mean those of the Infanta) that from the Dukedoms of Britany, Aquitain, and the like, that came to the Crown of France by women and are inheritable by women, she cannot be in right debarred; as neither from any Succession or Pretence to England, if (either by the Bloud-Royal of France, Britany, Aquitain, or of England itself) it may be proved that she hath any interest thereunto, as her favourites do affirm that she hath, by these reasons following.

Finis.

[Note in another hand.] Premier cahier du discours de ce qui cest passè en l'affaire des prestres anglois faict a Rome le $4^{e}$ nouēbre 1602.

6. Memorial to the Pope regarding the Sentence of the Inquisition, August 12."

Beatissime Pater

54, f. 113

Licet ijs omnibus, quæ à Sanct ${ }^{\text {te }} V^{\prime}$ ra et Ills ${ }^{\text {mis }} \mathbf{S}^{\text {ti }}$ Officij Cardinalibus in causa nostra declarata et terminata sunt, obedire simus paratissimi, captiuantes sensum et intellectum nostrum in obsequium potestatis et auctoritatis uestræ: tamen cum quæ ad pacis perpetuitatem sunt, quærimus, fratrumque nostrorum pro hoc tempore ora et oculi sumus, tenemur in conscientia, tanquam fideicommissi, antequam ultima manus negocio nostro imponatur, Sanc ${ }^{\text {tis }}$ V'ræ considerationi proponere dubia quædam et difficultates, quæ in quibusdam dictæ declarationis capitibus nobis occurrunt.

Pmo Itaque quod ad Archipresbiteri personam attinet, videtur valde difficile et improbabile, ut ijs sacerdotibus, quibus cum

a There is no heading to this document in the original.

VOL. II. 
tàm grauibus tàm leuibus de causis exercuit et adhuc exercet inimicitias, præsit pacifice; cum sit vir, (ut satis apparet) præter cætera ad iram et uindictam præceps, cum sit Judex sine iurisprudentia, et ità a nostris alienus, ut ne ad conspectum eius eos admittere dignetur; et cum seipsum nesciat regere, quin alieno consilio ad multa se nobisque indigna facillime impellatur, difficillimum erit alijs diù cum serenitate et tranquillitate, a Sanc ${ }^{\text {te }}$ V'ra desiderata, imperet, præcipue cum sit multum verisimile illum esse voto seu resignatione Jesuitam. ${ }^{a}$ Preterea autem cum constet omnes 12. Consiliarios, vel Assistentes Archipresbyteri, consilio ac nutu Patris Personij electos fuisse, et ipsorum nonnullos Societati Jesuitarum sese pariter astrinxisse, alios autem utpotè venationibus, aucupijs et similibus ineptijs continuò occu54, f. 113b. patos, cum magno uixisse et uiuere scandalo, omnes demum appellantibus inimicissimos esse, et ipso Arehipresbitero ineptiores ad gubernandum Ecclesiam, asperum uidetur tantorum Sacerdotum colla huiusmodi aduersantium superiorum noluntatibus premenda subijcere. Petimus itaque ut Archipresbiter omnino amoueatur, aut saltem alij Archipresbiteri in aliis Prouinciis equali authoritate instituantur, secundum illam quam in considerationibus nostris exhibuimus regiminis formam. Quibus consideratis si nihilominus Sanctas V'ra nihil de regiminis forma, nihil de persona Archipresbiteri mutandum decrenerit, certum est [nos] obedire, eamque obedientiam alijs omnibus nostris fratribus precipere et predicare.

Verumtamen si Sanc ${ }^{\text {ti }}$ 'ræe placuerit perpetuitatem huiusce magistratus ad unius anni aut biennij terminum restringere, magnum erit afflictis fratribus nostris sub tam duro domino solatium. Quod si parum uidebitur ista nostra postulatio opportuna, saltem inter Assistentes, et Consiliarios suos, depositis ineptioribus et Societati astrictis, aliqui ex nostris admittantur, quorum consilijs, et consensu in rebus agendis uti teneatur, et familiariter congrediatur, ut pristina omnium auersio hac mutua animorum coniunctione et consiliorum communione amoueatur.

a This appears to be a groundless suspicion. 
Dignetur etiain Sanc ${ }^{\text {tas }}$ V'ra cum Archipresbitero et Assistentibus qui uotum societatis emiserunt dispensare, aut ad ingressum Religionis coarctare, aut demum loco et officio regendis sacerdotibus sæcularibus amouere.

Quod ad communicationem cum Patribus Societatis attinet, petimus, ut hoc tàm ipsis Jesuitis quàm Archip̣pbro sub aliqua Censura Ecclesiastica iniungatur cuius absolutio Sanctissimo et 54, f. 114. successoribus reseruetur.

\section{De Eleemosynis.}

Quod ad eleemosynarum caput attinet, in quo omnium ferè Sacerdotum, et Catholicorum egentium (quorum infinitus est numerus) salus et uita sua est, uidentur fratres nostri qui in carceribus, premente inopia, mente exciderunt, et qui extrema sunt passi, tàm in uinculis quam qui liberius in uinea D'ni laborant (idque non solum sciente et consentiente sed et præcipiente Archipresbitero) perperam admonitione ista leuari.

Ad Patres autem Societatis cum maxima eleemosynarum moles, tum ipsorum hac in re exquisita diligentia tum quorumdam collectorum laycorum beneplacito, deuoluatur, quæ de ratione ab ijs exigenda proposuimus uidentur ampliori consideratione digna.

\section{De Appellationibus.}

De appellationibus ad Vrbem et ad IIl ${ }^{\text {mum }}$ Protectorem difficultates oriuntur ex parte sacerdotum aliquæ quibus satisfieri uix poterit, paupertas nimirum et impossibilitas sine uitæ periculo Regnum egrediendi, ut appellationes factas prosequantur. Ex parte Ill ${ }^{\text {mi }}$ Protectoris, in huiusmodi causis et controuersijs inexercitatio, et rerum nostrarum imperitia; licet enim Princeps sit nobilissimus, suauissimus et omni uirtutum genere ornatissimus, tamen appellationes istiusmodi (si modo in Regno ad neminem concedatur recursus sed immediatè ad Vrbem sit recurrendum) 54, f. 114b.

- That is, the order prohibiting such communication. 
recursus ad Ill ${ }^{\text {mos }}$ aliquos Cardinales, qui in causis nostris magis sunt uersati, saltem ad tempus donec ista penitus sit sedata tempestas, desideratur.

Quod ad libros attinet, omnes libros qui aliquid contra ordinem aut institutum societatis continent, aut contra aliquam priuatam è Societate personam, quod probare non possimus, et una heresim aliquo modo sapiunt: aut contra bonos mores uel sillabam unam habeant, Rothomagi, uel in Anglia, uel ubicunque impressos improbamus et damnamus, et improbari et damnari cupimus. Nominatìm autem libellum quendam supplicem ad Reginam Angliæ a Jesuitis conscriptum et promulgatum sine loco aut authore, continentem propositiones æquè scandalosas atque suspectas atque sunt illæ Watsoni, quem nunc accepimus et $\mathrm{S}^{\text {mo }}$ exhibuimus, condemnari cupimus, diem tamen, mensem, et annum exprimi petimus, ut distinguantur ab illis alij libri in eodem loco impressi qui ab Ills ${ }^{\text {mis }}$ DD. non improbantur.

Cum utrique parti iniungatur silentium et cessatio à librorum editione, communicatione, retentione et euulgatione, cumque aliqui è societate Patres primi et præcipui fuerunt in huiusmodi libris, literis, et scriptis edendis et promulgandis, ipsi uexò (quod in superiori Bulla nominatim non includebantur) nihil ad se spectare istum articulum asseuerarunt, ideoque liberrimè istiusmodi libros et scripta post promulgatam Bullam emiserunt cum perturbatione et scandalo Catholicorum omnium Anglorum, dignetur S. Sanc ${ }^{\text {tas }}$ ita aliquo modo clausulam istam explicare, ut omnes tàm Religsos 54, f. 115. quàm laycos et sacerdotes contineat, et una omne genus librorum, literarum, tractatuum quibus uiri alicuius Catholici fama iniuste uiolari poterit imposterum aut prius uiolata fuerat, quibus excitari ueteres uel concitari nouæ potuerint controuersiæ.

Postremo, ut Catholici omnes omni liberentur scrupulo de retroactis confessionibus, dignetur $\mathrm{S}$. Sanctas in cautelam declarare, omnes confessiones factas sacerdotibus appellantibus esse et fuisse ualidas, non obstantibus quibuscunque sententijs, censuris, aut suspensionibus ab Archipresbitero aut... Card. Caietano pro 
rebus ad hanc controuersiam spectantibus illatis; et quod ad facultates attinet, ut declarentur omnes esse in statu in quo ante inceptam hanc controuersiam fuerunt; in declaratione facultatum Archipresbiteri petimus explicari dubium illud de facultatibus tollendis, ne possit ab innocentibus pro arbitrio facultates auferre, et ne possit contra appellantes, qui per se uel per alios ad Vrbem uenerunt procedere (cum sit omnium excepto Vuatsono eadem ratio) nisi prius Roma à Sancts ${ }^{\text {mo }}$ uel eius iussu ab Ill ${ }^{\text {mo }}$ Protectore responsum habuerit. Insuper ut omnis uerborum ambiguitas tollatur in breuibus conficiendis ad lites futuras et contentiones præueniendas, Petimus etiam (ne insontes ex alieno delicto damnum patiantur) ut D'nus Guglielmus Vuatsonus (si ipse quid mali scripserit) Romam vel ad Nuncium Apostolicum in Gallia citetur, librorum suorum rationem ut reddat, et ut se purget aut pœnas debitas sustineat.

Ex literis Archipresbiteri datis nono maij facile iudicabit 54, f. 115b. Sanct ${ }^{\text {tas }}$ V'ra quantas ille de facultatibus tollendis et libris imprimendis excitauit tragœdias, etiam post ultimi Breuis Apostolici promulgationem, et quod nullam cum homine tam uiolente et imprudente sperare possumus pacem, nisi aut ipse penitus amoueatur, aut de facultatibus, libris, eleemosynis, consiliarijsque suis statuatur aliquid conforme postulatis et petitionibus nostris ; magis cæcam et promptam obedientiam exigunt a sacerdotibus secularibus Jesuitæ in Anglia cum Archipresbitero, quam in ullo, uel strictissimo religiosorum ordine exigitur, cum ipsi tamen Sanct $^{\text {ti }}$ V'ræ et superioribus suis obedientiam eo usque exhibent quoad talis submissio in rem suam cedat; quod in Sanct ${ }^{\text {tis }} V^{\prime}$ 'r hoc ulto Breui et in Nuncij Apostolici qui in Belgio uersatur mandato uidere licet de facultatibus non tollendis et libris non imprimendis.

Dignetur etiam Sanct ${ }^{\text {tas }}$ V'ra quamprimùm de istis difficultatibus statuere; ut tam leto nuncio quiescant omnes in partibus nostris tumultus, et ne sit fuga nostra in hieme, cum partim sumus senio confecti, partim ualetudine admodum infirma. 